\title{
Aspectos do Contratualismo Clássico na Formulação do Ideário do Estado Moderno: Subsídios para Análise do Pensamento Político Contemporâneo
}

\author{
Classic Contractual Aspects in the Formulation of \\ Modern State Ideals: Subsidies for the Analysis of \\ Contemporary Political Thought
}

\author{
Olegna Guedes* \\ Silmara Carneiro e Silva*
}

\begin{abstract}
Resumo: Parte-se, neste artigo, do suposto de que a análise de aspectos do contratualismo clássico auxilia na compreensão do ideário sob o qual se funda o Estado Moderno. A partir do jusnaturalismo, Hobbes, Locke e Rousseau formulam teorias que apresentam diferentes interpretações sobre conceitos que estruturam o pensamento político na modernidade. Suas concepções fornecem elementos teóricos que podem subsidiar a análise das relações entre o Estado e a sociedade civil em meio ao jogo ideopolítico no qual se estruturam, na contemporaneidade. A partir desse suposto, objetiva-se, neste artigo, trazer à tona aspectos fundamentais do contratualismo clássico e apontar de que forma eles auxiliam na análise do pensamento político contemporâneo.
\end{abstract}

Palavras-chave: Jusnaturalismo. Contratualismo. Pensamento político. Estado moderno.

\begin{abstract}
This paper is based on the assumption that the analysis of the aspects of classical contractualism helps the understanding of the ideals upon which modern state is founded. Based on natural law, Hobbes, Rousseau and Locke formulate theories that have different interpretations of concepts that structure modern political thought. Their conceptions provide theoretical elements that support the analysis of the relations between the state and civil society in face of the ideological/ political game in which they are structured nowadays. Based on this analysis, this papers aims to discuss the fundamental aspects of classical contratualism and demonstrate how they aid the analysis of contemporary political thought.
\end{abstract}

Keywords: Natural Law. Contractualism. Political Thought. Modern State.

"Dra. em Serviço Social pela Pontificia Universidade Católica de São Paulo (PUC-SP) Docente do Curso de Graduação e Pós Graduação em Serviço Social e Política Social da Universidade Estadual de Londrina (UEL). Bolsista Produtividade da Fundação Araucária -Apoio ao desenvolvimento científico e tecnológico do Paraná. E-mail: olegnasg@gmail.com

"Doutoranda em Serviço Social e Política Social pela Universidade Estadual de Londrina (UEL). Assistente Social da Secretaria de Estado da Família e Desenvolvimento Social do Paraná Ponta Grossa, Paraná, Brasil. E-mail: verdesilmara@yahoo.com.br. 


\section{Introdução}

Um dos aspectos que concorre para a construção do ideário que sustenta a concepção do Estado Moderno refere-se à construção de argumentos para explicar as suas relações com sociedade civil.

Dentre os autores que se debruçaram a desenvolver tais explicações destacam-se Thomas Hobbes, John Locke e Jean Jacques Rousseau, expoentes do contratualismo clássico. Suas construções teóricas versam sobre a formação do Estado e da sociedade civil, com base em uma relação contratual; sustentam suas análises numa acepção jusnaturalista; uma compreensão metafísica do homem em estado de natureza, portador de direitos naturais, anteriores ao Estado.

Denominados de autores jusnaturalistas, Thomas Hobbes, John Locke e Jean Jaques Rousseau conjugam sob as mesmas premissas, porém, com argumentos diversos; elementos que compõem o corpo ideológico, teórico e político que estão na base de sustentação, ou da crítica, do Estado Moderno.

Parte-se, neste artigo, do suposto de que a análise de aspectos desse contratualismo clássico auxilia na compreensão do ideário sob o qual se funda o Estado Moderno e fornece elementos teóricos que podem subsidiar a análise das relações entre o Estado e a sociedade civil em meio ao jogo ideopolítico no qual se estruturam, na contemporaneidade. A partir desse suposto, objetiva-se, neste artigo, trazer à tona aspectos fundamentais desse contratualismo e apontar formas pelas quais eles nos auxiliam na análise do pensamento político contemporâneo.

O artigo foi construído a partir de revisão bibliográfica limitada às seguintes obras: "O Leviatã" (Thomas Hobbes), "O segundo tratado sobre o governo" (John Locke), "Discurso sobre as desigualdades sociais" e "O Contrato Social" (Jean Jaques Rousseau). Procurou-se, nesta revisão, apreender as idealizações apresentadas pelos autores acerca da relação entre sociedade civil e Estado, a partir das seguintes categorias: estado de natureza, natureza do contrato social, liberdade, sociedade política (Estado).

\section{Hobbes, Locke e Rousseau e o Contratualismo Clássico: subsídios para a análise política contemporânea}

A formação da sociedade civil e do Estado compõe o movimento histórico-político que estrutura a sociedade moderna. Ambos, produtos da transformação das bases da estrutura econômica, social e política, inscrevem-se na história como instituições que dão sustentação à convivência humana na modernidade.

Os autores contratualistas preocupam-se em interpretar esse movimento político no período de gênese e consolidação do capitalismo, final do século XVII e primeira década do século XVIII. É um período que demarca a gênese da sociedade moderna, marcada pelos rebatimentos de uma nova forma de produção sob a qual se reconstruía a forma como o homem interpretava as bases de sua relação com o mundo e com os outros homens. Uma nova forma de sociedade nascia e, nela, idealizava-se a orientação da conduta e das escolhas humanas pela razão. Diante disso, diferentes perspectivas foram construídas pelos teóricos e, dentre elas, os contratualistas, para interpretar a constituição dos pactos políticos construídos à luz dos novos paradigmas emergentes nesse contexto.

Impera-se a racionalidade, sob a qual se selava uma nova explicação à relação para a necessária convivência entre os homens. É nesse contexto que emerge a necessidade de superação das explicações teológicas com relação à soberania, sob a qual se constitui um corpo político denominado Estado, que se relaciona e se sustenta a partir de uma determinada forma de associação: a sociedade civil. Essa nova estruturação política tem como uma de suas principais matrizes a formulação teórica de pactos societários, nos quais os indivíduos sociais, compreendidos como homens em estado de natureza, renunciam sua liberdade natural e, em troca, passam a ter direitos políticos assegurados pelo Estado. Nessa idealidade, para os contratualistas, na nova sociedade - a sociedade moderna - o estado de natureza dá lugar à sociedade civil e ao Estado. Funda-se, então, um ideário de soberania política baseada na ideia de um contrato. Daí advém a denominação de contratualismo.

Verifica-se que os contratualistas, embora tenham se debruçado a entender a sociedade

134 Emancipação, Ponta Grossa, 13, nEspecial: 133-143, 2013. Disponível em <http://www.revistas2.uepg.br/index.php/emancipacao 
moderna nascente, sob um mesmo conjunto de premissas interpretativas, cada filósofo contratualista, à sua maneira, construiu diferentes argumentos que sustentaram suas distintas interpretações sobre a soberania e ofereceram explicações que contribuem para a compreensão das relações ideológicas e políticas que compuseram o período de estruturação das bases da sociedade moderna. Portanto, as explicações teóricas construídas por Hobbes, Locke e Rousseau, sob as determinações do período histórico em questão, expressam particularidades da interpretação que cada autor faz acerca dos elementos históricos e políticos presentes no contexto em que estavam inseridos.

Dentre esses autores, Hobbes (1588-1679) é o precursor. Nasceu em um contexto político desfavorável para a Inglaterra. Viveu durante o período da reforma anglicana e acompanhou o efervescer da Inglaterra imersa na guerra dos 30 anos. Esses são alguns dos fatos históricos que corroboram para a formação de uma análise pessimista da realidade construída por Hobbes e que permitem identificá-lo como um sujeito temeroso mediante o contexto de fragilidade política no qual vivera. O próprio filósofo apresenta-se: "minha mãe pariu gêmeos, eu e o medo" (HOBBES apud RIBEIRO, 1984, p. 11). Ressalta-se, assim, na sua argumentação política, a defesa da troca da liberdade, que interpretava como inerente ao estado natural, pela segurança oferecida pelo Estado, corpo político formado mediante um contrato, por meio do consentimento dos homens.

Hobbes parte da premissa de que os homens em estado de natureza estão em condições de igualdade. Iguais tanto na força física como espiritual; voltam-se aos mesmos objetos; são instáveis; portadores dos mesmos desejos; e reúnem-se, sobretudo, motivados pelo desejo de se beneficiar da companhia do outro. E porque são iguais, e se voltam para a satisfação dos mesmos desejos, estão em constante disposição para a guerra, ou seja, são expostos a um estado de guerra de todos contra todos, traduzida na expressão Homo homini lúpus, que significa o 'homem é o lobo do homem'.

$\mathrm{Na}$ convivência entre os homens impera a desconfiança entre todos, sobretudo, pelo medo da morte violenta. Frente a tal desconfiança, torna-se fundamental o instinto de conservação, pelo qual os homens buscam valer-se de qualquer forma, a fim de salvaguardar suas vidas.
E, nessa busca, destacam-se três motivos para a constante discórdia: "Primeiro, a competição; segundo, a desconfiança; e terceiro, a glória." Hobbes (1979, p. 75). E, se é assim, porque então a necessidade da sociedade? Para o autor, a socialização se constrói devido ao desejo humano de segurança, mediante o medo da opressão. Assim, procura-se "[...] ajuda na associação, pois não há outra maneira de assegurar a vida e a liberdade." (HOBBES, 1979, p. 61).

No estado de natureza, para o autor, o homem não encontra outros meios para sua preservação e proteção que não seja o uso da força e ou da astúcia, o que não é seguro e nem estável para sua conservação. Nas palavras do autor,

[...] nenhuma maneira, de se garantir [a segurança] é tão razoável como a antecipação; isto é, pela força ou pela astúcia, subjugar as pessoas de todos os homens que puder, durante o tempo necessário para chegar ao momento em que não veja qualquer outro poder suficientemente grande para ameaçá-lo. $E$ isto não é mais do que sua própria conservação exige, conforme geralmente admitido. (HOBBES, 1979, p. 75).

Mediante o estado de natureza, na tradição hobbesiana, o direito natural compreende "[...] a liberdade que cada homem possui de usar seu próprio poder, da maneira que quiser, para a preservação de sua própria natureza, ou seja, de sua vida; [...]" (HOBBES, 1979, p. 78). A liberdade constitui-se, portanto, como um direito natural de conservação do homem, ao passo que considerando a lei da natureza, o homem deve se esforçar para viver em paz. Caso não alcance meios para tanto, "[...] pode procurar e usar todas as ajudas e vantagens da guerra." (HOBBES, 1979, p. 78).

A lei, na concepção hobbesiana, é entendida como um "[...] preceito ou regra geral, estabelecido pela razão, mediante o qual se proíbe a um homem fazer tudo o que possa destruir sua vida ou privá-lo dos meios necessários para preservá-la, ou omitir aquilo que pense poder contribuir melhor para preservá-la." (HOBBES, 1979 , p. 78). É, portanto, uma forma racional encontrada pelo homem para garantir a sua própria vida. Entretanto, a guerra é ainda um meio utilizado para a preservação do direito natural à vida. Daí a necessidade do pacto, sem o qual, o homem apenas em seu estado de natureza 
está em constante insegurança, medo e risco em relação à preservação da própria vida. Diante dessa condição, o homem consente ao Estado o poder soberano, mediante todos os homens.

Através da celebração de um contrato, o homem perde o direito natural à liberdade e em troca recebe proteção do Estado, o que estabelece um estado de segurança entre todos. Em Hobbes (1979, p. 80), o contrato configura-se como "[...] transferência mútua de direitos [...]". No caso do contrato firmado entre os homens para a formação do Estado, uma lei se constituiu necessária entre os homens.

Que os homens cumpram os pactos que celebrem. Sem esta lei os pactos seriam vãos, e não passariam de palavras vazias; como o direito de todos os homens a todas as coisas continuaria em vigor, permaneceríamos na condição de guerra. (HOBBES, 1979, p. 86).

O Estado hobbesiano configura-se num corpo político soberano capaz de proteger o homem do próprio homem e das vicissitudes inerentes à convivência humana em seu estado natural. Sobre o poder do Estado Hobbes (1979) afirma:

O maior dos poderes humanos é aquele que é composto pelos poderes de vários homens, unidos por consentimento numa só pessoa, natural ou civil, que tem uso de todos os seus poderes na dependência de sua vontade: é o caso do poder de um Estado. (HOBBES, 1979, p. 53).

Diante dos elementos teóricos construídos na teoria hobbesiana para interpretar a formação do Estado Moderno, verifica-se que no ideário construído por Hobbes, no Leviatã, o Estado absolutista configurava-se como a forma de governo que conseguiria melhor sanar as demandas humanas. Sua soberania seria suficientemente forte para impor limites aos homens, mediante a segurança proporcionada por algo que está acima de todos os homens. Sua função seria garantir a manutenção do direito do homem à preservação, minimizando os riscos desse feito, mediante os motivos que levam os homens à discórdia.

Para Ribeiro (2006, p. 31), a interpretação hobbesiana do Estado impunha a seguinte conclusão:
Quando, finalmente, firmamos todo o pacto pelo qual se institui o Estado, cada um de nós está cedendo algo no ato (o direito a todas as coisas, de que antes desfrutávamos) - e assim retira, de todos os outros, as razões para a suspeita recíproca. O que é absolutamente brilhante nesse caso é que o contrato de todos com todos faz com que cada qual ocupe as duas posições, a de quem desconfia (B) e a daquele de quem os outros deveriam desconfiar (A). Cada um (A), cedendo de imediato, retira dos outros (os B) a razoabilidade dele suspeitar. $O$ caráter simultâneo da operação faz com que, sendo todos A e B, a guerra encontre fim. (RIBEIRO, 2006, p. 31).

Nessa acepção hobbesiana de formação do Estado criam-se as condições políticas necessárias ao enfrentamento do estado de guerra de todos contra todos, uma situação inerente às relações entre os homens em estado de natureza, pois todos criam o Estado colocando-se cada qual em posições recíprocas, portanto na de desconfiar e na de ser alvo de desconfiança.

A partir do contrato, os homens firmam um compromisso no qual cada um não se coloca exclusivamente nas posições de sujeitos ou objetos de desconfiança. Mas, como cada qual sabe aprioristicamente que no estado de guerra poderia, a qualquer tempo, ocupar ambas as posições. Nessa nova relação, pautada na reciprocidade do contrato, o homem deixa de desconfiar do outro, na medida em que o outro demonstra ter deixado de desconfiar dele também. Constitui-se, assim, a reciprocidade que advém da formação do contrato e a afirmação do Estado enquanto instância política soberana, criada pelos próprios indivíduos, que se tornam no ato de criação autores do Estado, como forma de conquistarem uma forma de conviver com segurança.

Forma-se, portanto, uma sociedade civil regida por um corpo político governado por um homem artificial, maior que todos os outros homens, erigido por cada contrato, criado por esses homens, para governá-los - cuja soberania evita a morte violenta entre os homens e garante a preservação da vida e da paz entre todos. Cabe ao representante legal o papel de atuar, carregar a máscara, ou seja, portar um rosto que não lhe é próprio e, como ator, deve engajar nos seus atos, a vontade (o ato) dos homens (dos outros). Como autores, que concordaram com o pacto, cabe aos 
homens apenas obedecer ao governante para o qual entregaram, racionalmente, o poder de atuar e de agir (Hobbes, 1979). O poder político apresenta-se, portanto, em Hobbes, simultaneamente como produto da razão e resultado de sua impotência.

Um contraponto a essa concepção de soberania constitui-se o formulado por John Locke (1641-1704), filósofo inglês que se destaca como um dos principais formuladores do liberalismo. Locke foi crítico do absolutismo monárquico e teórico da burguesia em ascensão no final do século XVII.

Inserido na chamada Época de Ouro, na Inglaterra que estendia seu domínio sobre o mundo, Locke (1979) afirmou que na monarquia absolutista imperava um estado de guerra continuado entre o conquistador e o homem cativo, que se submetera à condição de súdito diante do soberano. Sobre o poder absoluto, considera que

Livrar-se de semelhante força é a única segurança de preservação; e a razão ordena considerar como inimigo à própria preservação aquele que arrebatar a alguém a liberdade que a assegura, de sorte que quem tenta escravizar a outrem se põe com ele em estado de guerra. (LOCKE, 1979, p. 40).

E, com relação ao estado de guerra, Locke o considera como "um estado de inimizade e destruição; [...]." (LOCKE, 1979, p. 40). Mas, contrapondo-se aos argumentos de Hobbes, afirma que nenhum poder superior na Terra poderia se sobrepor à liberdade do homem constitutiva de seu estado de natureza. Este, para Locke, configura-se como uma situação na qual os homens gozam de perfeita liberdade e igualdade. Tais conceitos, em Locke, são introduzidos em sua interpretação do estado de natureza, como pilares de sustentação à condição dos homens de dispor de suas posses e pessoas (KUNTZ, 1997).

A liberdade é compreendida, na interpretação liberal, como um estado em que os indivíduos dispõem de perfeitas condições para a preservação de sua propriedade e igualdade. Não é nada além do que a igual condição entre os homens de preservá-la. Condição esta, recíproca a todos que a possuem.

Kuntz (1997, p. 5) aponta que a perspectiva de "indiferenciação de poder" sustenta o perfeito estado de liberdade e de igualdade em Locke.
O estado de natureza tem uma lei de natureza para governá-lo, que a todos obriga; e a razão, que é essa lei, ensina a todos os homens que tão só a consultem, sendo todos iguais e independentes, que nenhum deles deve prejudicar a ordem na vida, na saúde, na liberdade ou nas posses. (LOCKE, 1979, p. 36).

Verifica-se, em Locke, que tanto a liberdade, como a igualdade são condições apriorísticas ao indivíduo e, portanto, não se configuram como finalidades de uma construção coletiva. A liberdade e a igualdade, para Locke, estão presentes no estado de natureza e são próprias dos indivíduos. "A liberdade natural do homem consiste em estar livre de qualquer poder superior na Terra [...]." (LOCKE, 1979, p. 43).

Partindo da referida lógica de estruturação das concepções de liberdade e igualdade, para Locke a concepção de estado de natureza constitui-se um estado de igualdade, no "[...] qual é recíproco qualquer poder e jurisdição, ninguém tendo mais do que qualquer outro [...]" (LOCKE, 1979, p. 35).

A formação da sociedade civil, que congrega representantes da classe dos indivíduos proprietários é, nesse sentido, uma sociedade de homens livres e iguais. Iguais em condições de preservar a própria propriedade.

Nessa interpretação lockeana, destaca-se a associação da liberdade à igualdade formal como sinônimo de justiça, em detrimento à desigualdade das condições materiais de existência, em que sua discussão está cativa ao seio das relações entre os proprietários. Conforme Kuntz (1997), a igualdade para Locke possui dois componentes essenciais: um positivo e outro negativo. O positivo é "[...] a comunidade da espécie e das faculdades características de cada um de seus indivíduos. O outro, indicado de forma negativa, é a ausência de subordinação transitiva." (KUNTZ, 1997, p. 6).

Para Locke, os homens convivem sob 'jurisdição recíproca'. O que significa que cada um, fazendo parte de um corpo, tem a responsabilidade pela sua autopreservação. A preservação do corpo de indivíduos que representa a humanidade.

Assim, no estado de natureza, conforme a lei de jurisdição recíproca, todos têm poder de empreender ação que tenha por objetivo a autopreservação e ainda que enseje punir qualquer 
um dos indivíduos, que no estado de natureza coloque em risco a autopreservação - a preservação do conjunto de homens.

Segundo Kuntz (1997, p. 7), "Para a 'preservação de toda a humanidade, a execução da lei da natureza é, naquele estado, (no estado de natureza) posto nas mãos de cada homem"'. (parênteses nossos). Explicita-se, aqui, a preocupação de Locke em sustentar a preservação da sociedade enquanto conjunto de homens proprietários. Portanto, a preservação da propriedade é elemento agregador do conjunto de homens na sociedade burguesa.

A burguesia compõe a sociedade civil explicitada por Locke. Seus argumentos de sustentação da liberdade e da igualdade enquanto bases das relações entre os homens são os princípios de sustentação das relações econômicas burguesas - bases para a agregação da sociedade civil como corpo político construído em prol da manutenção de seus interesses.

Locke, portanto, levanta argumentos centrais para consolidação do ideário da burguesia e torna-se um dos expoentes teóricos dos princípios políticos que davam sustentação à sua manutenção da burguesia no poder. Ressalta-se, entre esses argumentos, a defesa da propriedade privada no rol de direitos naturais do homem, associada à igualdade e à liberdade.

Baseado, ainda na doutrina jusnaturalista, Locke interpreta a propriedade privada como resultado do trabalho humano livre e a liberdade como uma condição anterior à formação do Estado, portanto inerente ao estado natural. Argumenta que o estado de natureza se configura como um estado de "[...] perfeita liberdade para ordenar-Ihes as ações e regular-Ihes as posses e as pessoas conforme acharem conveniente, dentro dos limites da lei da natureza, sem pedir permissão ou depender da vontade de qualquer outro homem." (LOCKE, 1979, p. 35).

Inserido nessa lógica, a propriedade privada, interpretada como fruto do trabalho humano livre, constitui-se um direito natural e, portanto, não deve se submeter a um poder soberano exterior ao próprio homem porque posterior, em termos ontológicos, à propriedade privada, intrínseca ao homem em seu estado de natureza.

A propriedade é extensão do trabalho humano. É fruto da apropriação do homem através de seu trabalho, daquilo que Deus deu em comum a todos os homens - o mundo e razão. Deus, afirma o autor, concedeu "[...] a terra e tudo quanto ela contém ao homem para sustento e conforto da existência." (LOCKE, 1979, p. 44). Locke (1979, p. 44) diz que

[...] embora a terra e todas as criaturas inferiores sejam comuns a todos os homens, cada homem tem uma propriedade em sua própria pessoa; a esta ninguém tem qualquer direito senão ele mesmo. $O$ trabalho de seu corpo e a obra das suas mãos pode dizer-se, são propriamente dele. Seja o que for que ele retire do estado que a natureza lhe forneceu e no qual o deixou, fica-lhe misturado ao próprio trabalho, juntando-se-lhe algo que lhe pertence, e, por isso mesmo, tornando-o propriedade dele.

O direito natural da propriedade, na teoria política de John Locke, uma das principais bases do liberalismo, tem como um de seus pilares fundamentais a formação de uma sociedade política, com vistas à garantia de leis necessárias para defesa e proteção da vida e dos bens; haja vista que, segundo o autor, embora todos os homens, no estado de natureza, sejam livres e iguais; não há garantia de segurança da propriedade.

$\mathrm{Na}$ referida teoria política, o objetivo do governo seria, então, garantir a segurança e paz entre as pessoas para que possam gozar das "[...] propriedades que tiverem e desfrutando de maior proteção contra quem quer que não faça parte dela" (LOCKE, 1979, p. 71).

O Estado, nessa perspectiva, não se resume, portanto, no coletivismo e ou em uma tirania, mas no corpo político formado pelo consentimento da maioria dos indivíduos pertencentes à sociedade civil. A gênese da sociedade é atrelada à necessidade dos indivíduos garantirem o que os levou a aceitá-la: a propriedade privada, um direito natural (LOCKE, 1979).

A sociedade civil é considerada o estado de união de todos os homens em um corpo que possui leis comuns para que os indivíduos possam apelar quando tiverem situações de controvérsias entre si e que serve para proteger a propriedade privada, enquanto forma de autopreservação das relações entre os homens no âmbito de um Estado, no qual a propriedade é considerada um direito natural e, portanto inviolável, nem por qualquer um dos indivíduos pertencentes à sociedade civil, nem pelo Estado. 
O governo civil, para Locke, é, portanto, resultado do consentimento dos indivíduos e tem por finalidade a preservação da propriedade, mediante as leis estabelecidas entre os membros da sociedade civil.

Diferentemente da concepção de Estado em Hobbes, na qual o Estado é soberano a todos os homens e detentor de toda a liberdade que pertencia aos indivíduos no estado de natureza, em Locke o Estado possui uma única e bem definida finalidade - a preservação da propriedade. Assim, o Estado se constitui em um corpo político a serviço dos proprietários, da defesa de seus bens e da legitimação da ordem capitalista burguesa, nascente na Inglaterra, no final século XVII.

Conquanto, o liberalismo de Locke se constituiu historicamente em uma teoria política que pressupunha a superação da ordem monárquica; a consolidação da burguesia como classe dominante na sociedade moderna nascente; e a defesa da propriedade privada, da vida e da liberdade dos burgueses, como condição para a dominação econômica e política da burguesia na modernidade.

Enquanto o desenvolvimento e a expansão econômica ainda estavam sob o comando régio, a burguesia buscava no liberalismo os argumentos centrais para a formação do Estado, sob o comando de um governo que não interferisse nas relações sociais inerentes à sociedade civil.

Assim, a liberdade econômica e a propriedade privada dela derivada mantinham-se inscritas nos liames da sociedade civil, conferindo à classe burguesa a hegemonia econômica e política da sociedade.

Nessa lógica, ao Estado incumbe-se um papel instrumental; a soberania política estava relacionada ao exclusivo cumprimento das leis construídas pelos indivíduos pertencentes à sociedade civil. A garantia das condições para a defesa da propriedade e a manutenção das relações sociais conforme estabelecidas no seio da sociedade civil são as ações delegadas ao Estado liberal.

A defesa da propriedade frente aos indivíduos que não fazem parte do pacto é necessária, na medida em que se julgam tais indivíduos como não possuidores de razão para contrair o referido pacto.

Nessa perspectiva, as classes pobres, emergentes em meio ao desenvolvimento das condições econômicas e políticas e ideológicas de estruturação do capitalismo e do estado liberal, eram tidas como uma ameaça à propriedade privada. Resta, portanto, ao Estado, o uso da força e da violência para reprimir e castigar aqueles que viessem a perturbar a ordem estabelecida pela sociedade civil e política, cuja burguesia constitui a classe dominante.

Em Locke, portanto, a noção de igualdade não contempla as noções de coletividade. Os indivíduos não proprietários aparecem, em sua argumentação, como homens desprovidos de razão, não pertencentes ao pacto social e excluídos da sociedade civil. Portanto desiguais em condições não só econômicas, mas também políticas.

Igualdade em Locke não é sinônimo de igualdade política e não contempla igualdade de condições econômicas entre todos. Apenas justifica a coesão dos indivíduos da classe burguesa, que sobrepostos à classe dos despossuídos, julgam-se iguais entre si e livres para preservar suas propriedades, manter seus interesses e reprimir aos demais indivíduos por não serem compatíveis com a perspectiva de sociedade civil construída sob os limites da ideologia burguesa.

Ao analisar as interpretações lockeana e hobbesiana, segundo Várnagy (2006), percebe-se que existem pontos que correspondem a uma mesma lógica de pensamento. Tais pontos são os seguintes:

[...] a convenção individualista do homem, a lei natural como lei de autopreservação, a realização de um pacto ou contrato para sair do estado de natureza, e por último, a sociedade política como remédio contra os males e problemas do estado de natureza. (VÁRNAGY, 2006, p. 57).

Entre os autores jusnaturalistas, Rousseau (1712-1778) abre um novo debate, ampliando os horizontes da discussão teórica do contratualismo clássico. O referido autor considera que esses, ao examinarem os fundamentos da sociedade, "[...] sentiram todos a necessidade de voltar até o estado de natureza, mas nenhum deles chegou até lá." (ROUSSEAU, 1973, p. 241). Compreende tal estado como contrário à "guerra de todos contra todos" formulada por Hobbes e à associação entre perfeita liberdade e igualdade como sustentáculos para defesa da propriedade. 
Parte do suposto que esse estado natural é o da perfeita harmonia entre o homem e a natureza, no qual o homem goza de plenas possibilidades de utilização do mundo; sem divisões.

O espírito humano não é, portanto, originalmente competitivo e conflitivo; tais características derivam da história (ROUSSEAU, 1979). E é por ela que se torna possível apreender a gênese e o desenvolvimento da sociabilidade humana conflituosa.

Um marco histórico, para Rousseau, é a sociedade civil. É a partir dela que nasce a propriedade, e a consequente desigualdade entre os homens. Rousseau (1973, p. 265) afirma que "O verdadeiro fundador da sociedade civil foi o primeiro que, tendo cercado um terreno, lembrou-se de dizer isto é meu e encontrou pessoas suficientemente simples para acreditá-lo." Assim, confrontando as posições teóricas de Hobbes e Locke, Rousseau deflagra o ato de formação da propriedade privada, vinculando-a à fundação da sociedade civil, enquanto estado de sua preservação entre os homens.

Se para Hobbes a sociedade civil era um estado de plena segurança de todos e para Locke um estado de paz e proteção de todos os homens, de suas vidas e de suas propriedades, para Rousseau, ela não passa de um estado em que o homem deixa de ser senhor e passa a ser escravo da natureza. "Tornando-se sociável o escravo, torna-se fraco, medroso e subserviente, e sua maneira de viver, frouxa e afeminada, acaba por debilitar ao mesmo tempo sua força e sua coragem." (ROUSSEAU, 1973, p. 247). Ricos e pobres convivem sob relações pautadas nas necessidades derivadas da preservação da propriedade.

A sociabilidade baseada nesse estado de desigualdade passa a reificar as relações humanas; configura-se como utilitarista e constituída por relações de trabalho fundadas na escravidão e na miséria; e dela deriva o lucro dos ricos. Rompe-se, portanto, a igualdade natural e se estabelece um estado de maior desordem, no qual o trabalho alienado e a propriedade privada se constituem nas bases de sustentação da sociedade civil.

Rousseau (1973, p. 274) argumenta que

Os ricos, de sua parte, nem bem experimentaram o prazer de dominar, logo desdenharam todos os outros e, utilizando seus antigos es- cravos para submeter outros, só pensaram em subjugar e dominar seus vizinhos, como aqueles lobos famintos que, uma vez comendo carne humana, recusam qualquer outro alimento e só querem devorar homens.

É para essa sociedade que Rousseau procura construir uma saída, na qual os homens pudessem selar um poder supremo que defendesse todos os membros comuns. A sociedade política seria, neste ideário, aquela na qual o homem poderia reencontrar a sua liberdade, na medida em que cada um cedesse um pouco para que se alcançasse a vontade geral de toda a sociedade. O bem comum seria o objetivo do contrato social.

No contrato social rousseauniano não há, portanto, garantia de interesses particulares. Ao contrário, a vontade geral que dele deriva é a expressão de todos os homens que participam pessoalmente do corpo político. Nessa síntese entre o homem particular com o homem político constrói-se uma noção de soberania coletiva e essa soberania possui limites, impostos pelos membros do corpo político.

Para Rousseau (1973, p. 54),

Assim como a natureza dá a cada homem poder absoluto sobre todos os seus membros, o pacto social dá ao corpo político um poder absoluto sobre todos os seus, e é esse mesmo poder que, dirigido pela vontade geral, ganha, como já disse, o nome de soberania.

O corpo político expressa o coletivo dos homens. O povo é o protagonista, de forma que a liberdade civil passa a ser sinônimo de liberdade natural e igualdade natural é também política. "Cada um de nós põe em comum sua pessoa e todo o seu poder sob o supremo comando da vontade geral e haverá de receber ainda cada membro como parte indivisível do todo." (ROUSSEAU, 1973, p. 39).

Conforme Reale e Antiseri (1990, p. 771),"Rousseau destaca, com extremo vigor, a interiorização da vida social e dos seus deveres. Não há nada de privado. Tudo é público ou, pelo menos, deve tornar-se tal."

Rousseau (1973, p.52) afirmara que

[...] a vontade geral é sempre certa e tende sempre à utilidade pública; donde não se segue, contudo, que as deliberações do povo 
tenham sempre a mesma exatidão. Deseja-se sempre o próprio bem, mas nem sempre se sabe onde ele está. Jamais se corrompe o povo, mas frequentemente o enganam e só então é que ele parece desejar o que é mau.

Assim, para Rousseau, o Estado é o corpo político garantidor da vontade geral, que é o resultado das deliberações do povo. O soberano deve ser guardião da vontade do povo. Assim, no Estado deve sempre prevalecer a vontade geral às vontades particulares. Portanto, para Rousseau (1973, p. 41),

Cada indivíduo, com efeito, pode, como homem, ter uma vontade particular, contrária ou diversa da vontade geral que tem como cidadão. Seu interesse particular pode ser muito diferente do interesse comum. Sua existência, absoluta e naturalmente independente, pode levá-lo a considerar o que deve à causa comum como uma contribuição gratuita, cuja perda prejudicará menos aos outros, do que será oneroso o cumprimento a si próprio.

Em contraposição à concepção de Estado hobbesiana, para Rousseau o poder do Estado é limitado, deve sempre passar pelo crivo do povo e respeitar a vontade geral. Ou seja, o homem não renuncia a sua liberdade para viver sob a proteção de um Estado, mas encontra a sua liberdade na medida em que é parte constituinte do próprio Estado. Para Rousseau (1973, p. 43), o Estado,

[...] perante seus membros, é senhor de todos os seus bens pelo contrato social, contrato esse que, no Estado, serve de base a todos os direitos, mas não é senhor daqueles bens perante as outras potências senão pelo direito de primeiro ocupante, que tomou dos particulares.

Com efeito, a vontade geral para Rousseau não se confunde com as vontades particulares, assim como a propriedade, na visão rousseauniana, deve estar submetida ao Estado, que através do contrato social torna-se senhor de todos os bens. Assim, contrapõe-se às concepções de Estado formuladas por Locke, na medida em que o Estado rousseauniano não preserva a propriedade enquanto direito natural. Ao contrário, os bens, a natureza e tudo o que há na sociedade torna-se indivisível, na medida em que se busca o bem comum, em detrimento dos interesses individuais.
A soberania é, então, coletiva e o Estado, por sua vez, constitui-se funcionário do povo, que se constitui nos membros do corpo político. "Pelo pacto social demos existência e vida ao corpo político." (ROUSSEAU, 1973, p. 59). Enquanto um corpo político criado pelo ato de vontade de seus membros, o Estado da visão rousseauniana constitui-se

[...] uma pessoa moral, cuja vida consiste na união de seus membros, e se o mais importante de seus cuidados é o de sua própria conservação, torna-se-lhe necessária uma força universal e compulsiva para mover e dispor cada parte da maneira mais conveniente a todos. (ROUSSEAU, 1973, p. 54).

Verifica-se, portanto, que enquanto Hobbes demarca uma posição de defesa do absolutismo monárquico, Locke dá sustentação à dominação política burguesa. Rousseau, contrapondo-se à tirania de um rei e à oligarquia de um grupo e/ou classe social, incorporou em sua teoria a formação de elementos que estruturam um corpo político que contribui para a sustentaçãodo Estado Democrático, a partir da construção da noção da 'vontade geral'.

Contudo, envolto de uma posição totalitária, acabou por desembocar na defesa de um Estado ético e totalitário (REALE; ANTISERI, 1990). O Estado era, portanto, na interpretação rousseauniana, um corpo político que deveria garantir ao homem o bem comum e a sua liberdade, na medida em que o próprio homem se transformava em parte constitutiva do próprio Estado.

Hobbes, Locke e Rousseau, portanto, foram autores que compuseram um conjunto de elementos que contribuiu para a filosofia política moderna, fundando explicações que dão sustentação à interpretação do Estado e da sociedade civil para a formação dos fundamentos da construção da modernidade.

Para Hobbes (1979), a formação do Estado moderno se dava em decorrência da necessidade de por fim à 'guerra de todos contra todos'; e preservar o direito de conservação do homem em uma condição de segurança e paz. Para Locke (1960), a mediação do Estado era necessária em virtude da necessidade da 'preservação da propriedade'. Já para Rousseau (1979) a sociedade política, por ele denominada, tinha por objetivo a garantia da 'vontade geral' de todos os homens. 
Entre Hobbes, Locke e Rousseau, este último é o que mais se diferencia, desde a noção de estado de natureza, como na questão da soberania do Estado, que se diferencia radicalmente, na medida em que para a visão rousseauniana esta possui origem no povo e pretende preservar a vontade coletiva. Assim, nem a segurança individual, nem a propriedade burguesa são elementos importantes em sua análise, pois a vontade geral não constitui para Rousseau a soma das vontades individuais, mas é uma construção coletiva.

Essas interpretações, próprias da filosofia política moderna, formam a base de sustentação da formação das relações entre Estado e sociedade civil na modernidade e compõem os conteúdos ideopolíticos presentes no âmbito das diferentes perspectivas ideopolíticas que sustentam o debate democrático na contemporaneidade. Sejam elas pautadas no liberalismo, calcadas na liberdade do indivíduo superior e acima do Estado e ou críticas desse modelo, sejam pautadas por questões inerentes à cultura da participação direta do cidadão na política e/ ou crentes na relevância do Estado enquanto instituição forte, capaz de suprimir a guerra e garantir um estado de segurança mútua para toda a sociedade, todas representam o desenvolvimento político e ideológico, historicamente construído na modernidade e tornam-se substrato para a interpretação dos conflitos, desafios e possibilidades acerca dos 'pactos possíveis' no âmbito das relações entre Estado e sociedade civil na contemporaneidade. São, portanto, calcadas no jusnaturalismo presente nas diferentes interpretações contratualistas.

Diversos foram os aspectos levantados pelo contratualismo clássico que ainda estão presentes no debate político e ideológico na contemporaneidade e servem de sustentação para a compreensão da importante contribuição dos autores Hobbes, Locke e Rousseau para a fundamentação dos pactos firmados entre a sociedade e o Estado na contemporaneidade. Neste artigo, destacaram-se alguns desses aspectos considerados relevantes para o debate acadêmico atual em torno de estudos sobre as relações entre o Estado e a sociedade civil.

Atualmente, os autores contratualistas são revisitados quando da análise de questões como os novos arranjos político-institucionais; a participação popular; a governança e a governabilidade pública; entre outros estudos que envolvem interpretações sobre a democracia e questões correlatas, nas quais a participação dos cidadãos e a constituição do Estado e da própria sociedade civil vão sendo construídas em meio ao histórico desenvolvimento da sociabilidade humana, no seio da moderna sociedade - democrática capitalista.

\section{Considerações finais}

Ao longo da discussão foi possível perceber, no que se refere aos pontos de semelhança e divergência entre os contratualistas, que Hobbes e Locke divergiram especialmente nos pontos sobre o estado de natureza, sociedade civil e Estado. No entanto, preservam os referidos elementos no âmbito de uma mesma estrutura lógica. Rousseau também se utiliza da mesma estrutura. Contudo, insere nessa estrutura uma nova interpretação fundada em uma concepção de soberania em que o indivíduo não está separado do Estado, mas se funde ao corpo político, se elevando à sua condição, quando forma o contrato e funda a sociedade política.

Percebe-se, assim, que a partir da construção do pacto, a liberdade passa a se constituir parte inerente ao próprio Estado. Funda-se uma interpretação em que a soberania estatal não é compreendida mais como exterior e/ou acima dos homens, mas tem origem e se consolida pela vontade geral.

Verificou-se que o contratualismo clássico guarda elementos importantes para a interpretação das relações entre o Estado e a sociedade civil na modernidade. A democracia, enquanto sistema de governo predominante na contemporaneidade, em suas perspectivas hegemônicas ou não, carregam per si elementos de sustentação que se explicam no seio dos aspectos levantados pelas teorias contratualistas. Os aspectos elencados pelos autores do contratualismo clássico contribuem na identificação de elementos relacionados aos conflitos de interesses, à relação público-privado, à legitimidade ou não do poder, ao uso da força estatal, à participação dos cidadãos nas deliberações públicas, à formação das instituições e aos arranjos participativos, dentre outros aspectos constitutivos da política.

Perspectivas liberais de democracia sobrevivem em conflito com perspectivas radicais de democracia. As questões da liberdade, da

142 Emancipação, Ponta Grossa, 13, nEspecial: 133-143, 2013. Disponível em <http://www.revistas2.uepg.br/index.php/emancipacao 
igualdade, da segurança, da proteção da propriedade fazem ainda, na atualidade, parte do caldo ideológico e político que compõe as discussões democráticas. Embora haja diversificação sociocultural, política, ideológica e cultural da sociedade, muito do que se observa no pluralismo democrático atual pode-se ressaltar que possui implícitos elementos discutidos pelo contratualismo clássico.

As lutas ideológicas, políticas, econômicas, sociais e culturais que conjugam historicamente valores contrapostos e perfazem o debate democrático na contemporaneidade estão direta e indiretamente vinculadas e/ou se explicam, em determinadas questões, quando analisadas à luz das diferentes perspectivas teóricas inerentes às teorias da filosofia política, nas quais o contratualismo ainda sobrevive como fundamento, em meio aos novos elementos teóricos que foram sendo agregados ao longo do desenvolvimento do Estado, da democracia e das lutas políticas travadas pela sociedade civil.

Considera-se que tais lutas constituem-se plurais, em meio às diferentes perspectivas de Estado e de sociedade que coabitam no espaço da política, mas os fundamentos do contratualismo clássico lançam mão de aspectos que iluminam a análise das complexas relações políticas e ideológicas presentes na sociedade contemporânea, servindo de parâmetro para a compreensão de muitas de suas contradições, conflitos e desafios na atualidade.

\section{Referências}

HOBBES, T. A. O Leviathan. São Paulo: Abril cultural, 1979.

KUNTZ, R. Locke, liberdade, igualdade e propriedade: texto da Conferência realizada por Rolf Kuntz no Instituto de Estudos Avançados da Universidade de São Paulo. 1997. Disponível em: <www.iea.usp.br/artigos>. Acesso em: 01, out., 2012.

LOCKE, J. Segundo tratado do governo civil. São Paulo: Abril Cultural, 1979.

REALE, R.; ANTISERI, D. História da filosofia: do humanismo a Kant. v. 2, 2. ed. São Paulo: Paulus, 1990.

RIBEIRO. R. J. Ao leitor sem medo: Hobbes escrevendo contra seu tempo. São Paulo: Brasilense, 1984.
Thomas Hobbes, ou: a paz contra o clero. In: BORON, A. (Org.). Filosofia política moderna: de Hobbes a Marx. São Paulo: CLACSO, DCP-FFLCH, USP, 2006, p. 19-43.

ROUSSEAU, J. J. O discurso sobre a desigualdade humana. São Paulo: Abril Cultural, 1979.

1973.

Do contrato social. São Paulo: Abril Cultural,

VÁRNAGY, T. O pensamento político de John Locke e o surgimento do liberalismo. In: BORON, A. (Org.). Filosofia política moderna: de Hobbes a Marx. São Paulo: CLACSO, DCP-FFLCH, USP, 2006, p. 45-79. 